\title{
Sport, Sexuality, and the Production of (Resistant) Bodies: De-/Re-Constructing the Meanings of Gay Male Marathon Corporeality
}

\author{
William Bridel \\ University of Ottawa \\ Geneviève Rail \\ University of Ottawa
}

\begin{abstract}
Placing the sporting body and Michel Foucault's technologies of power and of the self at the center of our research inquiry, this article explores the ways in which 12 Canadian gay male marathoners discursively construct their bodies within and beyond the marathon context. Thematic analysis of the research materials (gathered through guided conversations, written stories, and the first author's research journal) revealed four main themes: self-governed bodily practices, body modification, the marathoning body as resistant to dominant representations of male corporeality in gay culture, and transformative potential. Following Foucault, materials were further submitted to discourse analysis through which we uncovered the appropriation of and resistance to dominant discourses. This analysis suggested the subjects' discursive constructions as "hybrid" creations located both within, and sometimes in contest to, dominant discourses of physical activity, running, and the male body in gay culture. Our research explores the experiences of gay male athletes through a sociological lens that differs from the present literature, which has largely drawn on hegemony theory. It also adds new insights into distance running as a social phenomenon.
\end{abstract}

Centré sur le corps sportif et les technologies du pouvoir et du moi de Michel Foucault, cet article explore les façons dont 12 marathoniens gais canadiens construisent discursivement leur corps à l'intérieur et à l'extérieur du contexte marathonien. Une analyse thématique des données provenant de conversations, de récits écrits et du journal personnel du premier auteur révèle quatre thèmes :

Bridel is with the University of Ottawa, 69 Union St., Ottawa, ON. Rail is with the University of Ottawa, 451 Smyth, Ottawa, ON. 
les pratiques corporelles autogouvernées, la modification corporelle, le corps marathonien qui résiste aux représentations corporelles dominantes dans la culture gaie, et le potentiel transformateur. Suivant une approche foucaldienne, les données ont été soumises à une analyse de discours qui permet de révéler l'appropriation des discours dominants ou une résistance à ces derniers. Notre analyse suggère que les constructions discursives des sujets sont des créations « hybrides » situées quelque fois au sein des discours dominants sur l'activité physique, la course et le corps mâle dans la culture gaie, mais aussi quelque fois en opposition à ces discours. Notre étude examine les expériences des marathoniens sous une lentille sociologique qui diffère des écrits principalement collés à la théorie de l'hégémonie et jette une lumière nouvelle sur la course de longue distance comme phénomène social.

Over the past 20 years, many scholars have pointed to the usefulness of applying the theories of Michel Foucault to studies of sport and physical activity (Andrews, 1993, 2000; Markula, 2003, 2004; Pringle, 2005; Rail \& Harvey, 1995; Whitson, 1989). Such a turn has placed studies of sporting bodies at the center of research questions and agendas. In particular, scholars have noted the use of a Foucauldian framework by feminist sport theorists to deconstruct gendered power relations within sport and physical activity milieus (Chapman, 1997; Markula, 2003, 2004; Pringle, 2005; Rail \& Harvey, 1995). Our interest in Foucauldian perspectives of the body frames this study of self-identified gay male marathon runners.

More specifically, we use a Foucauldian framework to explore the technologies of power and of the self within the bodily practices of a group of gay male marathoners. We are interested in the ways in which gay marathoners discursively construct their bodies within and beyond the marathon context. We consider in particular the marathoners' recitation of, and resistance to, various dominant discourses of the body - discourses of physical activity, running, and dominant representations of the male body in gay culture. Such considerations, we feel, augment the existing bodies of research on gay male athletes and sociocultural studies of distance running. In the case of the former, studies largely exclude gay men participating in individual sport, and in the latter, sexuality has not been an area of focus with perhaps one exception (van Ingen, 2004). We begin by highlighting the scholarly texts that work as a starting point for our research.

\section{Considering Contemporary Inquiries of Gay Males' Experiences of Sport}

Although the use of a Foucauldian perspective has become prevalent in the sociology of sport, such does not specifically apply to the body of work interrogating gay male sporting experiences. Rather, studies of gay male athletes have drawn on Gramsci's (1971) hegemony theory and, more specifically, Connell's (1995) concept of "hegemonic masculinity." These follow academic explorations of sporting masculinities, which suggest how hegemonic masculinity subordinates both women and other types of masculinities (Messner, 1997). At the risk of oversimplifying, we can say that numerous studies of hegemony and gay males' experiences of sport have highlighted the expected performance of orthodox forms 
of sporting masculinity, both within mainstream and categorical sporting spaces. This includes performances by closeted gay athletes who are not openly gay in order to "pass" within their chosen sporting spaces (Hekma, 1998; Le Blanc, 2002; Pronger, 1990) and by openly gay athletes who seek to gain acceptance from their (ostensibly) heterosexual team/club mates before and after disclosing their sexuality (Anderson, 2002, 2005). Performances of hegemonic sporting masculinity may include playing with aggression and force, making critical contributions to the "winningness" of the team or club, and/or participating in a "culture of silence" (Anderson, 2002; Connell, 1995; Le Blanc, 2002; Pronger, 1990). Participation in the culture of silence may include the continued participation of "openly" gay athletes in heterosexist and/or homophobic dialogue in the various contexts of a sporting environment. ${ }^{1}$ This suggests that gay male sexuality in the sporting domain may only be acceptable when it is accompanied by a performance of the dominant form of sporting masculinity.

Contemporary academic studies have also pointed to the reproduction of hegemonic notions of sport in general within categorical sporting spaces. This includes a continued focus on competition and domination of opponents and the prioritization of victories over social networking (Elling, De Knop, \& Knoppers, 2001, 2003; King \& Thompson, 2001; Price \& Parker, 2003; Pronger, 2000b; Wellard, 2002). In brief, though these sporting spaces may become a "safe" place for lesbian and gay athletes, the "common sense" practices of sport seem not to differ all that much.

Undoubtedly, the academic literature on gay male athletes provides important insights into the continued problematic influence of dominant heteronormative discourses of sexuality and gender within both mainstream and categorical sporting spaces. We explore elsewhere the constructions of gender and sexuality within the marathon context (see Bridel \& Rail, 2006) drawing from a similar framework. In this article we wonder if the application of a different theoretical lens may offer another interpretation or reading of gay male sporting bodies, thus contributing to the small but growing body of literature. Here, we turn to Foucault. We are particularly interested in the practices and discursive constructions of gay male marathon bodies and the resistant possibilities they might possess.

\section{Distance Running in Sport Academy}

A Foucauldian perspective of the body has not yet been specifically applied to empirical studies of distance running; instead, the literature (beyond myriad biomedical studies) has largely explored the positive and negative outcomes of participation in distance running. Positive outcomes have been suggested to include improved health, a sense of personal achievement (Major, 2001; Ogles, Masters, \& Richardson, 1995; Smith, 2000; Summers, Machin, \& Sargent, 1983), and the acquisition of a greater sense of "self" through participation and success (Hockey, 2005b; Major, 2001; Smith, 2002). Negative outcomes of participation in distance running have been primarily related to the sustaining of injury, which seems to be an almost taken-for-granted state of being within this milieu (Hockey, 2005b; Major, 2001) and which can also be seen to have an impact on a runner's "athletic identity" (Allen-Collinson, 2003; Hockey, 2005a). On the prevalence of injury, 
Hockey has noted that, "[n]arratives of injury (along with narratives of performance) predominate ... and the spectre of injury is part of commonplace discourse and concern" (2005b, para. 4.5).

Though the injured might be commonplace within this particular social milieu, body modification through running is often referenced as a primary participatory motivation and outcome. In this instance, body modification has been considered as the desire to lose weight, to change musculature and/or shape, or to become more "physically attractive" (Major, 2001; Ogles et al., 1995; Smith, 2000; Summers et al., 1983; van Ingen, 2004). The idea of running as a practice of body modification has been attributed to contemporary representations of healthy bodies propagated through media images and texts. In a realist analysis of the embodiment of class, gender, and age through distance running, Abbas (2004) has proposed that though running has oft been promoted as an accessible activity that contributes to the pursuit of a "healthy lifestyle," there is concurrently a visual representation of a dominant body type in running texts that shapes participants' expectations and pursuits. Depictions of the distance-running body are often presenting it as lean, muscular, stereotypically masculine, and youthful. According to Abbas, this is a privileged body type that subordinates aging and/or female bodies-bodies that have become more prevalent in the running community. Visual representations of certain bodies also reproduce the body type that is often linked with distance running "success" (Johns \& Johns, 2000) despite the fact that most people seem to run for personal improvement and/or enjoyment (Major, 2001; Ogles et al., 1995; Summers et al., 1983).

Existing sociocultural and psychological studies of distance running serve as a useful starting point for our study. Our goal here is to accrue our understanding of distance running as a social phenomenon through the discursive constructions of marathon bodies provided by gay males active in the milieu. In our work, we seek to place marathon bodies at the center of inquiry, situated within a framework that draws on the concept of discourse and those of the technologies of power and of the self. Thus, we next consider insights from previous Foucauldian-based sport studies.

\section{Discipline, Surveillance, and Transformation}

Foucault (1972) theorized that the body is a subject of technologies of powertechnologies established through discourses of "expertise" such as medicine, law, and science. Through these discourses or "truth games" (Foucault, 1988), individuals develop knowledge about themselves, while bodies become the site of domination through technologies of power and practices of discipline and surveillance. Foucault (1995) used the metaphor of Jeremy Bentham's panopticon to describe the normalizing "gaze" that leads to a self-policing of the body. The panopticon (a prison design in which prisoners are unaware of when they are being watched but always aware of the possibility) works to regulate human behavior as prisoners come to self-police to avoid punishment. Foucault envisioned the panoptic gaze within the general social realm; discourses and their acceptance as "truth" lead to panoptic mechanisms by which individuals self-regulate or self-govern their behaviors with no need for physical means of enforcement or punishment. Instead, this 
self-governance works to make each individual "his own overseer, each individual thus exercising this surveillance over and against himself" (Foucault, 1995, p. 155). In other words, discourses of expertise work to produce docile bodies through selfsurveillance or panopticism.

While the body as an object disciplined by social discourses may have become prominent in the classical age (Foucault, 1972), similar domination continues with various practices of discipline and self-regulation in contemporary times. Many have suggested that this is the case within contemporary systems of health, fitness, sport, and physical activity. Sport theorists have drawn from Foucault's technologies of power in different ways. Feminist interrogations of power, female sporting bodies, and constructions of femininity (Bartky, 1988; Bordo, 1993; Chapman, 1997; Evans, Davies \& Wright, 2004; Markula, 2000; Rail, 2006), as well as examinations of hierarchal power relations in high-performance sport (Johns \& Johns, 2000; Shogan, 1999), have all signaled the diverse ways in which sporting practices work to produce and then make use of docile bodies.

Pronger (2000a) has also drawn extensively from Foucault in his consideration of the physical fitness "industry." In particular, he has referred to contemporary discourses of health and fitness and the creation of optimal bodies as the "technology of physical activity." He has defined this as a "discourse of texts, socio-cultural practices, and bodily procedures that produce human life in controlled ways" (p. xiv). According to Pronger, there appears to be no escape from the powerful context in which idealized body images appear in the everyday social realm: "The omnipresence of these popular representations of the fit body undoubtedly contextualize the ways in which people read bodies" (p. 144). As such, contemporary technologies of physical activity work to normalize bodies according to (Westernized) social norms; male bodies are expected to be muscular, strong, and "fit," with the onus placed on the individual to create such a body type. Borrowing from Bourdieu, Pronger has also noted the importance of looking good (i.e., physically fit as defined through contemporary Western texts) as part of a "physical capital." According to this notion, the body comes to have exchange value in multiple respects: "The body has the social exchange value of tastes, needs, and habits that operate in the social exchange within and between social groups" (p. 105). Therefore, the body is both produced and valued through constructed social norms. Such disciplining and valuing has been suggested to have different meanings for different subjectivities. For example, Bartky (1988) usefully highlights the ways in which discourses of femininity work to produce highly gendered bodies. It has also been noted in academic texts that gay men are often subjected to a particular bodily production-one that is heavily muscled and "hyper-masculine" (Kassel \& Franko, 2000; Pronger, 2000a; Wood, 2004). Some have labeled this phenomenon the "buff agenda," an agenda that seeks to both hypermasculinize gay male bodies and to distance them from diseased connotations connected with the 1980s AIDS epidemic (Halkitis, 2000).

Though Foucault (1972) argued that individuals within any given society are subjects of power/knowledge and come to acquire their understanding of the social through dominant discourses, he also considered power beyond domination, proposing that power is in everyone and everywhere $(1980,1988)$. In other words, power is not structural, but practiced. Such a conceptualization of power offers the possibility that subjects can resist practices of domination and patterns of social regulation. This is significant when considering ideas of transformation. As Rail 
and Harvey have noted, it allows for "the existence of a body escaping repression: an active, autonomous and powerful body" (1995, p. 175). Transformation, Foucault argued, allows for a certain emancipation or, as he wrote, "a certain state of happiness, purity, wisdom, perfection or immortality" (1988, p. 18). Foucault referred to this particular use of power as the technologies of the self-specific practices by and through which subjects knowingly constitute themselves within and in resistance to power. There are varying ways in which such practices can occur: self-care, self-knowledge, and mastery of the self.

Academic inquiries of sport and physical activity, though largely highlighting technologies of power, have also considered technologies of the self and the transformative possibility of sporting practices (Chapman, 1997; Johns \& Johns, 2000; Markula, 2003, 2004). We are interested in similar questions of transformative possibility in sport and, in particular, for those "othered" by dominant discourses of sexuality. Our empirical investigation thus brings us to interrogate marathon practices and bodies, as well as their articulation with power and regulatory discourses.

\section{Eleven Runners and a Researcher who Runs: Voices From the Road}

We collected our qualitative materials for this study through an autoethnographic methodology; more specifically, we adopted a reflexive ethnographic approach (Ellis \& Bochner, 2000). Blurring the distinction between self and other, we understand autoethnography as a form of research that provides opportunity for the researcher to incorporate his or her own life experiences with the experiences of those being studied (Reed-Danahay, 1997). In this instance, both the first and second authors self-identify as queer; the former is an active marathoner. We assume the perspective that the researcher's voice should not be considered any less relevant when discussing personal experiences in the social phenomenon being studied and that such an approach is entirely useful when considering embodied experiences of sport and physical activity.

Beyond William's (the first author) experiences in marathoning, we also draw on the experiences of 11 other runners recruited via purposive sampling of Canadian Front Runner groups - categorical running clubs for the gay, lesbian, bisexual, transgender, and queer (GLBTQ) community. All participants self-identified as gay or queer. ${ }^{2}$ Whereas, on average, group members had run 10 marathons, all of them had run at least 4; their number of years of involvement in the sport ranged from 5 to 15 years. All considered themselves "recreational marathoners" though the abilities of the group varied; one participant had recorded several sub-3-hour marathons, while two others generally ran the distance in more than 4 hours. The youngest participant was 30 and the oldest 60 ; the average age was 36 years. All identified as Euro-Canadian, and all had completed at least an undergraduate degree. Participants were employed in various occupations that would position most in the middle- to upper-socioeconomic classes. Three Canadian geographic locations were represented: the greater Toronto area, Ottawa, and Vancouver.

The narratives interrogated for this study were collected through in-depth conversations, written personal stories collected via e-mail, and William's research journal. We used conversation and personal narrative guides to focus the research, 
and at the same time encouraged a certain degree of flexibility. Both guides focused on marathon experiences and motivations and different notions of the body and bodily practices. Qualitative materials were collected between July and October, 2005 , and the study was conducted in compliance with regulations established by the University of Ottawa Research Ethics Board.

The qualitative materials were transcribed, and the texts were then transferred into QSR NUD*IST VIVO and coded. The texts were submitted first to a thematic analysis. Organizing the material thematically allowed us to identify the major themes and subthemes emerging from the texts. Of particular interest were the discursive constructions of the body. Following this thematic and "vertical" analysis, we looked at the narratives comparatively (or transversally). This approach allowed us to gain a better understanding of the articulations of sexuality with the diverse experiences of the body within this particular sporting space. These steps led to a further interrogation of the text through the use of discourse analysis. We drew from Foucault's concept of discourse as practices that shape subjects and constitute them: "[they] systematically form the objects of which they speak. Discourses are not about objects; they constitute them and in the practice of doing so conceal their own intervention" (1972, p. 49). With this understanding, our analysis involved an attempt to deconstruct "truths" that shape the participants' understandings of the social and their subject position therein, in particular as related to dominant discourses of the body within contemporary technologies of sport and physical activity.

Once the texts had been interrogated, participants were provided an opportunity to read a brief "story" that we created from portions of the participants' narratives. The "composite story" was meant to summarize the main themes and experiences as discursively constructed by the participants. Returning the story to them was a way for us to verify whether we had adequately captured these themes and experiences. This also helped to "validate" the results of our analysis. Each participant was asked to read the story and to discuss how it represented his own ideas and experiences (in full or in part). All participants who reviewed the story indicated that they felt adequately represented by the story. We use excerpts from the participants' narratives in the present paper to give voice to this particular group of gay athletes. Participants self-selected or were assigned pseudonyms, which are used here to protect their identities.

The thematic analysis revealed discursive constructions unique to each of the 11 participants and the first author. At the same time, there were clear trends with regards to four themes related to constructions of the corporeal. We consider these (interrelated) themes here: (a) self-governed disciplinary marathon practices and physical limitations; (b) marathoning as a practice of body modification; (c) the (suggested) contrast between the marathon body and dominant representations of the male body in gay culture; and (d) (individual) transformative potential.

\section{Marathon Practices: Discipline and the Limits of the Body}

Participants constructed their physical investment in the marathon context in largely similar ways, which we have labeled as marathon practices. These included the interconnected practices of the physical act of running, diet, and rest and recovery. 
First and foremost, participants' training regimens were largely homogeneous; the regimens included running independently with categorical running groups (i.e., the Front Runners), and, for 8 of the 12, with "mainstream" training groups. ${ }^{3}$ The physical act of running included runs of various lengths and intensities, each with its own purpose. For most participants, a high-mileage training week consisted of 60 or more kilometers of running. Leigh's commentary represents an approach to marathon training that resonated throughout the narratives:

If I'm training for a marathon, the training week is five days of running, two days of not running. And, the running is of different distances with each day of the week. Often they have different speeds as well. I really believe that if you want to have a good experience in marathoning, it's really important to do very good training.

Participants also seemed to pay special attention to diet, which was most often referenced as "appropriate" caloric intake so as to avoid weight gain. Such dietary focus was constructed as being connected to both marathon training and health in general. Bjorn's comment is representative of the subjects' rather similar constructions of marathoners' diets:

We eat a remarkably low amount of processed food.... We like cooking fresher meals and that sort of thing. I don't know that we eat necessarily healthy all the time but, for the most part, I think we have a pretty balanced diet. You know, we don't sidle up to the old country buffet and pile on the macaroni and cheese.

Rest and recovery were also constructed as integral to marathon training. Many participants made reference to getting proper rest so as to maximize training opportunities and to let their bodies recover from (and for) the physical act of running. The voluntary training regimen to which all participants subscribed led to demands on the body that were constructed as grueling, exhausting, challenging, and brutal. At the same time, such demands of the body were positioned as necessary in order to achieve personal marathoning goals. The following commentary highlights such a construction of the body and efforts to exceed physical limits:

Whenever my body starts to feel fatigue and is starting to get into that zone where, you know, I'm not having, where I'm not enjoying myself. And I usually just tell myself to, kind of: "Keep your pace, keep your pace, keep your pace." And essentially, that's how I get myself out of that rut. It's pushing yourself to kind of a boundary that, you know, not a lot of people actually go to that level, go to that boundary. It's just training to go past what you think you're capable of doing so that your body is at its optimal for success. (Jim)

Marathon practices seemed to rely on what we could call a marathon body subject to disciplinary practices and careful self-surveillance. Paradoxically, despite this calculated and largely self-regulated approach to marathon practices, the participants constructed marathon bodies in ways that always brought back the issue of injury. Perry's commentary represents a typical construction of marathon bodies, injury, and limitations: 
When I take on training for a marathon, I push, push, push myself. This of course results in injuries, fool that I am. I had to cancel out on the Vancouver Marathon two years ago with a hamstring injury, which unfortunately is reoccurring. I HATE being injured to the point of not being able to run, train, compete. I don't feel whole, complete, integrated unless I am training.

Conversations with our participants were similar to those noted in other studies in that they were steeped in injury-related narratives (Hockey, 2005b) to the point of considering injury to be more or less inevitable (Major, 2001). In Perry's and other participants' conceptualizations of their bodies, physical limitations, and injury, the importance of just being able to run emerged. Participants primarily identified themselves as "runners," a discursive construction that relied on the disciplinary practices of marathoning for the production of a functional, though often injured, body. The disciplining of this body was constructed as largely self-policed; however, the participants also ran with running groups. Though the hierarchal relationship of coach/official and athlete evidenced in high-performance sport (Johns \& Johns, 2000; Shogan, 1999) was not as highly regulated within these recreational training groups, the provision of specific training plans and group runs, as well as the use of other runners' abilities as extra incentive to improve running, worked together as a regulatory power, much in the same way that physical education classes create docile bodies (Evans et al., 2004; Pronger, 2000a; Rail, 2005). Furthermore, pushing the limits of the "marathon body" is in line with dominant discourses of highperformance sport in that it is seen as a necessary means through which one would bring one's body to its optimal functional state: "Maximum efficiency in resource management is the ideal embodiment of the modern subject of the technology of physical activity" (Pronger, 2000a, p. 217). This point becomes even more relevant when we consider the discursive construction of marathon practices as a way to modify the body for benefits both within and beyond the marathon context.

\section{Body Modification: Questions of “Lookin' Good”}

The construction of the body as an object to be modified through marathon practices was evident in all the subjects' stories, although the motivations varied. Some subjects discursively constructed bodily modification in relation to a gain in efficiency within marathoning. Others constructed it in relation to beautification and ensuing social gains, and others still as a combination of both. We will leave to the physiologists the specific question of whether a sport can shape someone's body; our interest here is rather in the discursive constructions of bodily modification within and beyond the marathon context.

For some of the subjects, body modifications (e.g., losing weight, gaining leg muscle, "toning") were conceptualized as by-products of training that would enable the achievement of personal marathon goals with little to no emphasis on "aesthetics." Other participants constructed the modification of their bodies through marathoning as providing benefits within and beyond the sport itself. In this regard, many participants (including the first author) constructed marathon involvement as a way to lose weight, to change body shape, or simply to become "healthier," each of which was positioned as having aesthetic implications and bringing personal satisfaction: 
I, like many gay men, am a bit narcissistic. Running, for me, keeps my body weight down. You have to look good. It also has health benefits as well. I do have hypertension. Marathons help to keep my BP in check. Type 2 diabetes in males is a familial trait. I hope marathon running will help with this possible aspect of my health. (Mary Ann) ${ }^{4}$

Though there were differing conceptualizations of body modification through marathon practices, the subjects' discursive constructions of "typical" marathon bodies were similar. Although participants did recognize a wide range of body types, most pointed to an "optimal" body shape and size. This "optimal marathon body" was constructed as muscled but lean with strong, efficient legs, an advanced cardiovascular endurance system, and a less-developed upper body. According to Shawn, the optimal marathon body is "sinewy and looks under-fed, but is fit and efficient." Others constructed it as "sleek and thin." Regardless of their terminology, all subjects conceptualized themselves as a total or partial embodiment of this discursive construction. Some positioned this embodiment as their "natural" build. Others commented that though looking very much the part of a runner, such was not their "natural" morphology, but rather the end result of active participation in marathon practices. Here, we see the unquestioned use of modern, essentialist categories to classify the corporeal as being "natural" or "not natural." This binary, in fact, pervaded many of the narratives, which speaks to the prevalence of biomedical discourses as "truths" within the running milieu. Furthermore, the construction of the optimal body as "thin and sleek" suggests a recitation of normative ideas of "successful bodies" rooted in popular and academic discourses on running (Johns \& Johns, 2000), as well as the (re)production of corporeal typologies that dominate running-related media (Abbas, 2004; Markula, 2000; Smith, 2000).

Although to this point we have considered the discursive constructions of the body primarily within the marathoning context and the (re)production of dominant running discourse through active and voluntary participation in self-regulated marathon practices, marathoners are subjects of (and are located within) multiple and competing discourses of the body. Their bodies are created (physically and discursively) not only within the marathon context but also within the context of gay culture.

\section{Gay Marathon Bodies: Locating "Thin and Sleek" in "Buff" Culture}

Participants constructed their bodies not only as a vessel used in the achievement of personal goals within the sport of marathoning but also as a resource beyond the marathon context. In this regard, marathon bodies were constructed as projecting certain images beyond marathoning: healthy, aesthetically pleasing to others, and that "look good." The idea of "looking good" seemed particularly relevant within gay culture, a culture that was constructed as a space in which there were definite pressures to care about one's body. It is interesting, however, that there seemed to be specific representations of what this meant that were not in line with the discursive constructions of the marathon body. Leigh's statement is a good illustration of such constructions: 
Big chest, big arms, washboard abs. You know, that was sort of the three combination. And so, they, they were basically all breast meat! You know, they were these enormous men with these great big poitrines [chests]. And the other thing is that they didn't work on their legs. So they had these tiny little legs and enormous upper bodies. (Leigh)

Though recognizing the presence of other (marginalized) body types in the gay community (i.e., Bears, Otters, and "Twinks"), Leigh's construction was typical in that other participants similarly characterized the idealized gay male body in a largely homogeneous way and one dominant in gay male culture. This is not different from what has been found in a number of studies; the "buff" body is of high importance to gay men who may spend hours in fitness centers and gyms and participate in "risky" behaviors (e.g., disordered eating, steroid use) in order to achieve a heavily muscled, well-defined frame that is considered among most of their peers as aesthetically pleasing (Conner, Johnson, \& Grogan, 2004; Drummond, 2005; Halkitis, 2000; Russell \& Keel, 2002). The buff, hypermasculine image has been reported to be dominant in gay media and pornography (Drummond, 2005; Kassel \& Franko, 2000; Wood, 2004) and embodied in the creation of "gym bodies" that are put on display in gay spaces in an attempt to attract the male "gaze" (Duggan \& McCreary, 2004; Kassel \& Franko, 2000; Yelland \& Tiggemann, 2003). Despite the overwhelming presence of such physical and discursive representations, marathoners within our study offered some resistance to them. We illustrate this point with two further narratives:

Most marathon runners are really kind of lanky. Uh, most marathon runners don't really have a lot of definition in terms of arms, and chest, and back. We actually have more of a feminine body [laughs]. That's probably a more accurate description because we don't have those harder muscles, because if you're going to run that far, all those muscles are just going to get in the way. (Thomas)

They tend to be more muscled, more focused on upper-body strength. I know I've seen some physiques in certain ads and magazines and, it's like, to me they're gym body physiques. They don't really look like they're, uh, they're nice to look at, but they don't project a sense that they are trained to do something. So, they're not "working” bodies. (Rick)

Gay marathoners seemed thus to be part of milieus circulating very different body images: the "thin and sleek" marathoning body versus the "buff" gay male body. Both Thomas and Rick constructed their bodies as a form of resistance to male bodily images dominating the culture of which they are part (both discursively and through active involvement in the gay "community"). At the same time, there remained evidence of a conscious creation of bodies that project certain images beyond the marathoning milieu-despite not fitting the idealized gay body image, marathon bodies were still constructed as bodies that "looked good." Consider the following excerpt from Perry's narrative: 
Marathoning has changed my body totally. I am extremely lean, and in top training, ripped. I love the feeling of being ripped. True confessions, I WANT to look this way. I want to garner attention for my body; it makes me feel good.

And as Leigh similarly commented: "People tell me that I have a runner's body, and that's a nice compliment to have." Our subjects' bodies were also largely, though not exclusively, constructed as "masculine," which demonstrates the participants' adoption of subject positions within dominant gender discourses, an idea that we explore more fully elsewhere (see Bridel \& Rail, 2006). ${ }^{5}$

Here, we conclude that although there was a resistance to contemporary, dominant representations of the "buff" gay male body through the creation and valuing of "thin and sleek" marathon bodies, there was also a (re)citation of dominant discourses of physical activity and health that suggest that certain body types have more social exchange value than others (Pronger, 2000a). In other words, these constructions pointed to the reification of an aesthetic value associated with dominant physical representations of the body in contemporary Western texts or discourses. In this regard, the marathon body was constructed as having physical capital in so much as it constituted an embodiment of popular representations of a healthy body. Finally, though subjects constructed their selves and bodies in resistance to dominant representations of the gay male body, they still found a "place" for such bodies within gay culture. Such conceptualizations hint at the transformative meaning found within marathon experiences for our participants.

\section{Considering the Transformative Potential of Marathon Practices and Bodies}

The narratives of these runners, as well as the suggested interconnectedness of their marathon practices and body modification, speak to the idea that their marathon involvement has transformative possibilities and meanings for them. The positive sense of self seemingly achieved through marathon participation suggests that these gay men's particular sporting experiences might be read as transformative on an individual level. The following comment reflects a linking of marathon practices, body modification, and sexuality in a way that suggests such potential:

In the midst of an existing midlife-crisis mode, I happened upon a notice for Front Runners, the local gay running group, and, in an attempt to lose weight and become more comfortable with myself, I took the first step in coming out as gay and a runner. My enjoyment of running is certainly tied closely to the social component, as well as to weight control and better health. (Doug)

Another participant, Wolf, also closely linked his involvement in marathoning with the development of a greater sense of self: "[Running] was a meaningful way for me to identify with being gay and to embrace the gay world around me. I found myself more comfortable with identifying as a gay runner." Finally, William noted that marathoning was 
a way for my sexual and athletic identities to coexist in a positive way, something which I had not necessarily experienced in previous sporting spaces. Marathoning also allowed me the opportunity to produce a body with which I was comfortable, thus providing me with a greater sense of desirability to others.

We commented earlier that Foucault envisioned transformative potential through certain technologies of the self that allow for the attainment of "a certain state of happiness, purity, wisdom, perfection or immortality" (Foucault, 1988, p. 18). He suggested the possibility of specific practices by and through which subjects knowingly constitute themselves within and in resistance to power. Here, there seems to be a recitation of notions of transformation and happiness as discursive materials for the construction of marathon involvement and experiences. Foucault proposed that technologies of power and of the self do not exist in isolation from each other. Perhaps in the constructions of marathon practices and bodies by this particular group of gay subjects, such a theoretical perspective can be confirmed via empirical resources.

\section{Discussion and Conclusion}

Placing the body and the Foucauldian perspective at the center of research questions remains relevant to sport sociology, in particular when considering multiple subjectivities, sport, physical activity, and dominant discourses of the body prevalent in contemporary Western society. We suggest that this is another way to consider the intersection of gay sexuality and sport. Existing literature largely references gay male athletes as subjects of (and in some cases, contributors to) a propagation of the core tenets of sport and expected performances of orthodox sporting masculinity. Though our participants' discursive constructions of their bodies and marathon practices were gendered, we wonder still if their active, voluntary participation within this milieu and the resultant sense of personal achievement can be read as contesting dominant discourses that work to subjugate alternative sexualities within a world of sport often considered a (heterosexual) "male preserve" (Dunning, 1986). Further, following Miller (1998), we wonder if there are times when "men are not being men, when their activities might be understood as discontinuous, conflicted and ordinary, rather than interconnected, functional and dominant" (p. 433). This position allows us to look differently at gay male marathon bodies and their meanings.

\section{The Marathon Body as a "Hybrid" Creation}

The "production" of the marathon body as a conscious endeavor to be functional (however that may be embodied) and/or for aesthetic purposes suggests the presence of two sets of regulatory practices of the body. We propose then that subjects discursively constructed gay marathoning bodies as "hybrid" creations resulting from the subjects' interpellation by multiple and, at times, competing bodily discourses (i.e., discourses of health and physical activity, discourses of running, discourses 
of the idealized gay male physique, and discourses of gender and sexuality). Such conceptualizations seem similar to existing academic research on distance running in so much as the quest for "physical attractiveness" is often a motivator for participation (Major, 2001; Ogles et al., 1995; Smith, 2000; Summers et al., 1983). However, the Foucauldian paradigm further helps us to understand distance running as a social phenomenon-one that does not operate outside of discourse but rather as a discursive field through which docile bodies are produced in line with contemporary constructions of bodily practices and performances. In this vein, we see the present study as furthering Pronger's (2000a) work on the technology of physical activity. At present we are exploring this idea more fully in research on gay male runners' constructions of health and physical activity.

We have also considered the meaning of the marathon body within gay culture, recognizing our participants as subjects of multiple discourses. In this regard, turning to Foucault's (1988) notion that the body is never constructed outside of discourse is helpful-while constructions of gay male marathon bodies resisted one bodily discourse, another was reproduced. This result is not so different from feminist inquiries into sport and physical activity that have suggested that female sporting bodies go against some dominant discourses (thus, some transformative potential may exist) but are often created within technologies of power that propagate conventional images of femininity (Bartky, 1988; Bordo, 1993; Chapman, 1997; Markula, 2000).

In our research, despite the notion that bodily constructions have emerged as a rearticulation of dominant physical activity and running discourses, there still seems to be a conscious resistance on the part of subjects to the male body propagated by much of gay culture. Thus, individual transformative potential was suggested through the stated resistance to dominant representations of the gay male physique and the conceptualization of this resistance as "empowering" the "gay" self vis-à-vis corporeality. At the same time, we cannot overlook the reproduction of the dominant discourses of obesity and beauty within our participants' narratives, nor the prevalence of injury narratives. These speak to the paradoxical nature of the marathon context. On the one hand, marathon practices in which the participants actively engaged seemed to provide a sense of self-achievement and bodily satisfaction connected to a stronger sense of self, of which being gay was very much a part. On the other hand, these same practices largely led to injury. This raises interesting questions about the "health" practices of running and the subjects' individualistic and aesthetic constructions of health.

\section{Final Remarks}

In the end, have we achieved that which we set out to do? Our goal was to consider the intersection of sport, sexuality, and the male body in ways heretofore not considered within studies of gay athletes. Rather than focusing solely on external and repressive powers, perhaps the sporting experiences of gay men can also be considered as exercises of freedom in which varied modes of self may be created (Chapman, 1997). There is some evidence of this, though we are also cautious to note that we are speaking of a fairly homogeneous participant group: White, middle- to upper-class Canadian males living in major urban centers. Perhaps being "out" in sport, having access to the milieu and specific bodily practices therein, and 
thinking about participation in such transformative ways is a privilege reserved to a few. It is also likely important to consider transformative potential in terms of individual versus group perspectives. In this case, marathoning is a very individual sport and, as such, transformative potential is mostly restricted, in our thinking, to an individual level. Finally, we would like to suggest that Foucault offers a potential rethinking of the gay male sporting body and self, as well as a rethinking of their location within sporting spaces and discourses.

\section{Acknowledgments}

The authors would like to thank the editor and the three anonymous reviewers for their insightful and helpful comments. We would also like to thank Dr. Mary Louise Adams (Queen's University) and Dr. Dave Holmes (University of Ottawa) for their contributions to the text.

\section{References}

Abbas, A. (2004). The embodiment of class, gender and age through leisure: A realist analysis of long distance running. Leisure Studies, 23(2), 159-175.

Allen-Collinson, J. (2003). Running into injury time: Distance running and temporality. Sociology of Sport Journal, 20, 331-350.

Anderson, E. (2002). Openly gay athletes: Contesting hegemonic masculinity in a homophobic environment. Gender and Society, 16(6), 860-877.

Anderson, E. (2005). In the game: Gay athletes and the cult of masculinity. Albany, NY: State University of New York Press.

Andrews, D. (1993). Desperately seeking Michel: Foucault's genealogy, the body, and critical sport sociology. Sociology of Sport Journal, 10, 148-167.

Andrews, D. (2000). Posting up: French poststructuralism and the critical analysis of contemporary sporting cultures. In J. Coakley \& E. Dunning (Eds.), Handbook of sports studies (pp. 106-137). London: Sage.

Bartky, S.L. (1988). Foucault, femininity, and the modernization of patriarchal power. In I. Diamond \& L. Quinby (Eds.), Feminism and Foucault: Reflections on resistance (pp. 61-86). Boston, MA: Northeastern University Press.

Bordo, S. (1993). Unbearable weight: Feminism, Western culture, and the body. Berkeley, CA: University of California Press.

Bridel, W., \& Rail, G. (2006). Exploring gay male marathoners' discursive constructions of sexuality and gender (and the meaning of 26.2 miles). Manuscript submitted for publication.

Chapman, G.E. (1997). Making weight: Lightweight rowing, technologies of power, and technologies of the self. Sociology of Sport Journal, 14, 205-223.

Connell, R.W. (1995). Masculinities. Berkeley, CA: University of California Press.

Conner, M., Johnson, C., \& Grogan, S. (2004). Gender, sexuality, body image and eating behaviours. Journal of Health Psychology, 9(4), 505-515.

Drummond, M.J. (2005). Men's bodies: Listening to the voices of young gay men. Men and Masculinities, 7(3), 270-290.

Duggan, S.J., \& McCreary, D.R. (2004). Body image, eating disorders, and the drive for muscularity in gay and heterosexual men: The influence of media images. Journal of Homosexuality, 47(3/4), 45-58.

Dunning, E. (1986). Sport as a male preserve: Notes on the social sources of masculine identity and its transformations. Theory, Culture and Society, 3, 79-90. 
Elling, A., De Knop, P., \& Knoppers, A. (2001). The social integrative meaning of sport: A critical and comparative analysis of policy and practice in the Netherlands. Sociology of Sport Journal, 18, 414-434.

Elling, A., De Knop, P., \& Knoppers, A. (2003). Gay/lesbian sport clubs and events: Places of homo-social bonding and cultural resistance? International Review for the Sociology of Sport, 38(4), 441-456.

Ellis, C., \& Bochner, A. (2000). Autoethnography, personal narrative, reflexivity: Researcher as subject. In N. Denzin \& Y. Lincoln (Eds.), Handbook of qualitative research (pp. 733-768). Thousand Oaks, CA: Sage.

Evans, J., Davies, B., \& Wright, J. (2004). Body knowledge and control: Studies in the sociology of physical education and health. London: Routledge.

Foucault, M. (1972). The archeology of knowledge. New York: Harber Torchbooks. (Original work published in French in 1969).

Foucault, M. (1980). Power/Knowledge: Selected interviews and other writings 1972-1977. New York: Pantheon Books.

Foucault, M. (1988). Technologies of the self. In L.H. Martin, H. Gutman, \& P.H. Hutton (Eds.), Technologies of the self: A seminar with Michel Foucault (pp. 16-49). Amherst, MA: University of Massachusetts Press.

Foucault, M. (1995). Discipline and punish: The birth of the prison (2nd ed.). New York: Vintage Books.

Gramsci, A. (1971). Selections from prison notebooks. London: New Left Books.

Halkitis, P.N. (2000). Masculinity in the age of AIDS: HIV-Seropositive gay men and the "Buff Agenda." In P. Nardi (Ed.), Gay masculinities (pp. 130-151). Thousand Oaks, CA: Sage.

Hekma, G. (1998). “As long as they don't make an issue of it...”: Gay men and lesbians in organized sports in the Netherlands. Journal of Homosexuality, 36, 1-23.

Hockey, J. (2005a). Injured distance runners: A case of identity work as self-help. Sociology of Sport Journal, 22, 38-58.

Hockey, J. (2005b). Knowing the route: Distance runners' mundane knowledge. Sociology of Sport Online, 7(1). Retrieved June 21, 2005, from http://physed.otago.ac.nz/sosol/ contents.htm

Johns, D.P., \& Johns, J.S. (2000). Surveillance, subjectivism, and technologies of power: An analysis of the discursive practice of high-performance sport. International Review for the Sociology of Sport, 35(2), 219-234.

Kassel, P., \& Franko, D.L. (2000). Body image disturbance and psychodynamic psychotherapy with gay men. Harvard Review of Psychiatry, 8, 307-317.

King, L., \& Thompson, P. (2001). "Limp-wristed, Kylie Minogue-loving, football-hating, fashion victims": Gay sports clubs-Providing for male members, challenging social exclusion? In, G. McPherson \& G. Reid (Eds.), Leisure and social exclusion (pp. 81102). London: Leisure Studies Association.

Le Blanc, R. (2002). "The first fifteen": Understanding the conspiracy of silence of gay rugby players in Aotearoa New Zealand. Unpublished doctoral dissertation, University of Otago, Dunedin, NZ.

Major, W.F. (2001). The benefits and costs of serious running. World Leisure Journal, $43(2), 12-25$.

Markula, P. (2000). I gotta do the marathon: Women's running as a truth-game. Aethlon, $X \operatorname{VIII}(1), 89-106$.

Markula, P. (2003). The technologies of the self: Sport, feminism and Foucault. Sociology of Sport Journal, 20, 87-107.

Markula, P. (2004). Tuning into one's self: Foucault's technologies of the self and mindful fitness. Sociology of Sport Journal, 21, 302-321.

Messner, M. (1997). Politics of masculinities: Men in movements. Thousand Oaks, CA: Sage. 
Miller, T. (1998). Commodifying the male body, problematizing "hegemonic masculinity." Journal of Sport and Social Issues, 22(4), 431-447.

Ogles, B., Masters, K., \& Richardson, S. (1995). Obligatory running and gender: An analysis of participative motives and training habits. International Journal of Sport Psychology, 26, 233-248.

Price, M., \& Parker, A. (2003). Sport, sexuality and the gender order: Amateur rugby union, gay men and social exclusion. Sociology of Sport Journal, 20, 108-126.

Pringle, R. (2005). Masculinities, sport, and power: A critical comparison of Gramscian and Foucauldian inspired theoretical tools. Journal of Sport and Social Issues, 29(3), 256-278.

Pronger, B. (1990). Gay jocks: A phenomenology of gay men in athletics. In M. Messner \& D. Sabo (Eds.), Sport, men and the gender order (pp. 141-152). Champaign, IL: Human Kinetics.

Pronger, B. (2000a). Body fascism: Salvation in the technology of physical fitness. Toronto: University of Toronto Press.

Pronger, B. (2000b). Homosexuality and sport: Who's winning? In J. McKay, M. Messner, \& D. Sabo (Eds.), Masculinities, gender relations and sport. (pp. 222-243). Thousand Oaks, CA: Sage.

Rail, G. (2005). De/Re/Construction of health: Physical activity and youth narratives of beauty. In Scientific proceedings of the 2005 International Sport Science Congress: Holistic perspectives on well-being (pp. 121-138). Chuncheon, Korea: Kangwon National University Press.

Rail, G. (2006). Éléments de réflexion sur la santé et la colonisation du corps féminin [Reflecting on health and the colonisation of women's bodies ]. In C. Bernier et R. St-Onge (Eds.), Penser la santé des femmes dans la diversité [Thinking of diversity in women's health] (pp. 235-255). Sudbury, Ontario: Éditions Prise de parole, Collection Agora.

Rail, G., \& Harvey, J. (1995). Body at work: Michel Foucault and the sociology of sport. Sociology of Sport Journal, 12, 164-179.

Reed-Danahay, D. (1997). Auto/Ethnography: Rewriting the self and the social. Oxford: Berg Publishing.

Russell, C.J., \& Keel, P.K. (2002). Homosexuality as a specific risk factor for eating disorders in men. International Journal of Eating Disorders, 31, 300-306.

Shogan, D. (1999). The making of high-performance athletes: Discipline, diversity, and ethics. Toronto: University of Toronto Press.

Smith, S. (2000). British nonelite road running and masculinity: A case of 'running repairs?' Men and Masculinities, 3, 187-208.

Smith, G. (2002). Racing against time? Aspects of the temporal organization of the runner's world. Symbolic Interaction, 25(3), 343-362.

Summers, J., Machin, V., \& Sargent, G. (1983). Psychosocial factors related to marathon running. Journal of Sport Psychology, 3, 314-331.

van Ingen, C. (2004). Therapeutic landscapes and the regulated body in the Toronto Front Runners. Sociology of Sport Journal, 21, 253-269.

Walton, T., \& Butryn, T. (2006). Policing the race: U.S. men's distance running and the crisis of Whiteness. Sociology of Sport Journal, 23, 1-28.

Wellard, I. (2002). Men, sport, body performance and the maintenance of "exclusive masculinity." Leisure Studies, 21, 235-247.

Whitson, D. (1989). Discourse of critique in sport sociology. Sociology of Sport Journal, $6(1), 60-65$.

Wood, M. (2004). The gay male gaze: Body image disturbance and gender oppression among gay men. Journal of Gay and Lesbian Social Services, 17(2), 43-62.

Yelland, C., \& Tiggemann, M. (2003). Muscularity and the gay ideal: Body dissatisfaction and disordered eating in homosexual men. Eating Behaviours, 4, 107-116. 


\section{Notes}

1. Anderson (2002) has likened the notion of the culture of silence to the US military's "don't ask, don't tell" policy (i.e., though present, gay sexuality within heteronormative sporting spaces largely remains unspoken). Culture of silence is a term used to explain the lack of discussion of homosexuality within sport-even after participants have "come out" to teammates and club members.

2. Though two participants self-identified as queer, we have used gay throughout the paper when referring to the sexuality of the participants as the majority selected this self-identifying label. That said, we recognize that there is nothing essential in the term gay; rather, it is part of the dominant sexuality discourse recited by most of the participants - an idea we explore elsewhere (see Bridel \& Rail, 2006).

3. The "mainstream" running groups in which the participants were active were most typically associated with running stores located in the cities in which the participants lived. These groups provided detailed training plans, as well as the opportunity to run with other athletes of a similar or higher skill level.

4. The name "Mary Ann" was chosen by one of the participants as his pseudonym. He explained that it was a nickname that had been given to him in elementary school and that he had reclaimed it as an adult.

5. Beyond gender, it is important to note the extent to which dominant discourses used by the runners are also classed and raced. Though beyond the scope of this particular project, insights into US distance running have revealed the extent to which race, class, and nationalism are evident in discourse, to the point where distance running has been considered a "White space" (Walton \& Butryn, 2006). 
Copyright of Sociology of Sport Journal is the property of Human Kinetics Publishers. Inc. and its content may not be copied or emailed to multiple sites or posted to a listserv without the copyright holder's express written permission. However, users may print, download, or email articles for individual use. 